\title{
An experimental investigation on the performance of a thermoelectric dehumidification system
}

\author{
P. Rakkwamsuk ${ }^{1}$, P. Paromupatham ${ }^{2}$, K. Sathapornprasath ${ }^{3}$, C. \\ Lertsatitthanakorn $^{2^{*}}$ and S. Soponronnarit ${ }^{2}$ \\ ${ }^{1}$ Materials Technology Division, School of Energy, Environment and Materials, King \\ Mongkut's University of Technology Thonburi, 126 Pracha Uthit Rd., Bang Mod, \\ Thung Khru, Bangkok 10140, Thailand \\ ${ }^{2}$ Energy Technology Division, School of Energy, Environment and Materials, King \\ Mongkut's University of Technology Thonburi, 126 Pracha Uthit Rd., Bang Mod, \\ Thung Khru, Bangkok 10140, Thailand \\ Tel. +00662470864; Fax: +006624279062 \\ *E-mail: charoenporn.ler@kmutt.ac.th \\ ${ }^{3}$ Department of Mechanical Engineering, Faculty of Engineering, \\ Srinakharinwirot University, 63, Moo 7, Ongkharak, Nakorn Nayok, 26120, Thailand
}

\begin{abstract}
A thermoelectric (TE) air-cooling system for dehumidifying indoor air in a building was investigated. The system was composed of $4 \mathrm{TE}$ modules. The cold sides of the TE modules were fixed to an aluminum heat sink to remove moisture in the air of a test chamber of $1 \mathrm{~m}^{3}$ volume, while a heat sink with circulating cooling water at the hot sides of the TE modules was used for heat release. The effects of input electric current to the TE modules and air flow rate through the heat sink were experimentally determined. The system's performance was evaluated using dehumidification effectiveness and coefficient of performance (COP). A suitable condition occurred at 18.5 A of current flow and 240 $\mathrm{W}$ of power being supplied to the TE modules with a corresponding cooling capacity of $149.5 \mathrm{~W}$, which gave a dehumidification effectiveness of 0.62 . Therefore, it is anticipated the proposed TE dehumidifier concept will contribute to the air conditioning system's reduction of room humidity.
\end{abstract}

Keywords: Thermoelectric; COP; Heat sink

\section{INTRODUCTION}

Humidity, one of the six primary factors that must be addressed in a thermal comfort environment [1] has attracted considerable attention in the fields of Heating, Ventilating, Air Conditioning and Refrigeration. Many criteria regarding indoor humidity have been implemented in recent years. Like Leadership in Energy and Environment Design, have stipulated that designers must limit indoor relative humidity that would otherwise cause dampness-related problems such as mold and microbial growth. Designers and researches have done considerable work to improve the indoor humidity environment. For example, Zafirah and Mardiana [2] demonstrated the use of an air-to-air energy recovery unit for reduction of humidity in a building. The intake air temperature was fixed at $35^{\circ} \mathrm{C}$. while the relative humidity was varied from 70 to $90 \%$. Experimental results showed reduction 
of relative humidity in the order of 1.30 to $3.05 \%$. Bassuoni [3] investigated the performance of an air dehumidifier using calcium chloride solution as the working desiccant material. He studied the effect of air flow rate, desiccant solution flow rate, desiccant solution temperature and concentration and packing thickness on dehumidification effectiveness. In early years, convectional air-conditioning systems (Vapor compression systems) were widely applied in real-world situations to couple and control the indoor temperature and humidity. However, convectional air-conditioning systems consume large amounts of electrical energy which cause a peak load on electrical networks, especially on hot summer days. Besides, the Freon in vapor compression system, once it starts leaking, will cause irreversible damage to the ozone sphere and exposes all life to ultraviolet radiation. Hence, a TE dehumidification system is proposed. TE technology can be used in two major operating models: TE generator and TE cooler. The TE cooler systems have no moving parts and do not employ a working fluid, which transfers heat from the cold side of the modules to the hotter side with consumption of electricity [4]. Due to advantages such as high reliability, low weight and flexibility in packaging and integration, the TE cooler systems are regarded as clean and active cooling methods widely used in military, aerospace, instrument and industrial products. However, only a few studies focus on TE cooler systems for solar stills. Rahbar and Esfahani [5] investigated a portable solar still integrated with TE cooling modules. The TE modules were used to enhance the temperature difference between the evaporating and condensing zones. Test results showed that the daily productivity and average energy efficiency were $0.25 \mathrm{~L} / \mathrm{m}^{2} /$ day and $7 \%$, respectively. Yildirum et al. [6] studied the concept of using a TE cooler in a portable solar still. They integrated the TE cooler into the system in order to improve the processes of both humidification and dehumidification. They reported the maximum daily productivity of the system and the value of COP of TE cooler. Dehghan et al. [7] developed the thermal modeling and exergetic analysis of a TE assisted solar still. Energy and exergy balance equations have been written for all components of a combined solar still with TE module. It was found that the daily average energy and exergy efficiencies of the solar still were $19.8 \%$ and $0.95 \%$, respectively. The rate of exergy destructions in solar still components is proportional to the incident solar intensity. The largest exergy destruction belongs to the TE module, which was $63.4 \%$ of the total exergy destruction. Irshad et al. [8] developed a TE air duct system; twenty four TE modules were used in the study. The TE air duct system reduced the room air temperature in the range of $1.2-5.3^{\circ} \mathrm{C}$ and relative humidity in the range of $5-31 \%$. The COP of the system varied from 0.392 to 0.697 under different operating input current. They [9] also studied thermal comfort of the TE air duct system. The optimum performance of the system occurred at 6 A input current. The system has met $80 \%$ of the acceptability criteria of the ASHARE Standard. From the literature reviews above, none has reported the TE dehumidification system for dehumidifying the air in a habitat. The main objective of this study was to maximize the dehumidifying rate of the TE dehumidifier. Dehumidification effectiveness was investigated.

\section{MATERIALS AND METHODS}

\section{System Description}

The entire experimental platform consisted of three parts: the TE cooler, test chamber and water cooling system (Figure 1). The TE cooler was composed of TE modules and heat sinks. The cold side of TE modules was attached to the cold side heat sink acting as a 
dehumidifier as shown in Figure 2. The rectangular fin heat sinks on the cold side and hot side were made of aluminum. The fins were $3 \mathrm{~mm}$ thick; $190 \mathrm{~mm}$ long in the horizontal direction and had a height of $32 \mathrm{~mm}$ from the base. There were 11 fins with pith of $3 \mathrm{~mm}$ on the base. Riffat \& Ma [10] and Sangmesh et al. [11] suggested that water-cooled force convection heat exchangers achieve excellent performance. Therefore, a water cooling system was used to release heat from the hot side of the TE modules. The water-cooling system was composed of the hot side heat sink installed in an aluminum box, a fan cooled the radiator and a driving pump. The fan-cooled radiator had a radiator area of $782 \mathrm{~cm}^{2}$ and a $12 \mathrm{~V} 36 \mathrm{~W}$ cooling fan to cool the heated water. When the system is operating, the water circulates and absorbs the heat of the hot side of TE modules and then dissipates it into the environment in the fan-cooled radiator. The pump consumed $40 \mathrm{~W}$. In this experiment four TE cooling modules (TEC1-12708, China) were used. The cold side heat sink was installed in a duct. The TE dehumidification was placed on the top of the test chamber. The test chamber had a volume of $1 \mathrm{~m}^{3}\left(1 \times 1 \times 1 \mathrm{~m}^{3}\right)$, installed inside a laboratory. The chamber had a door and no window. All of the walls were made of gypsum board $(0.9 \mathrm{~cm}$ thick, thermal conductivity $0.17 \mathrm{~W} / \mathrm{mK})$. Air was supplied by a $0.3 \mathrm{~m} \times 0.0 \mathrm{~m}$ nozzle diffuser located on the top of the test chamber. A blower was used to blow the air through the cold side heat sink and nozzle. The TE modules were connected in series with a direct current power supply regulated in the ranges of $0 \mathrm{~V}$ to $100 \mathrm{~V}$ and $0 \mathrm{~A}$ to $10 \mathrm{~A}$.

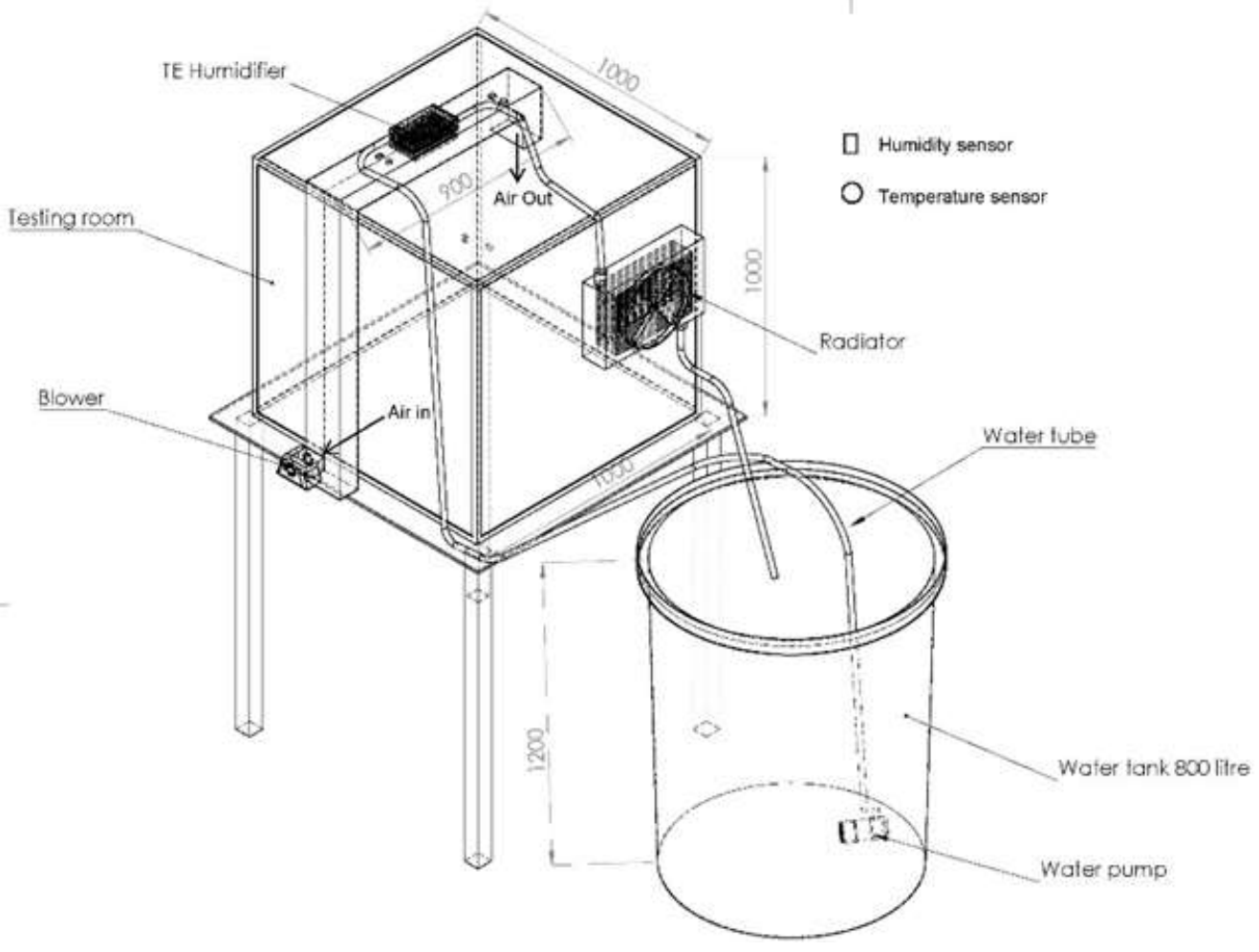

Figure 1. Schematic diagram of experimental set-up

The instrumentation in the test setup included sensors for temperature, humidity, air velocity and power input. The distribution of the sensors is shown in Figure 1. Thermocouples of type T were used to measure the temperatures of the hot and cold sides of TE modules, the water inlet and outlet and the air chamber. A humidity sensor was used to record the relative humidity of the air chamber. The air velocity passing through 
the cold side heat sink was measured by a hot-bulb velocity probe. The input current and voltage were measured with a multimeter. A data acquisition system was used to collect the data at regular 1 min intervals.

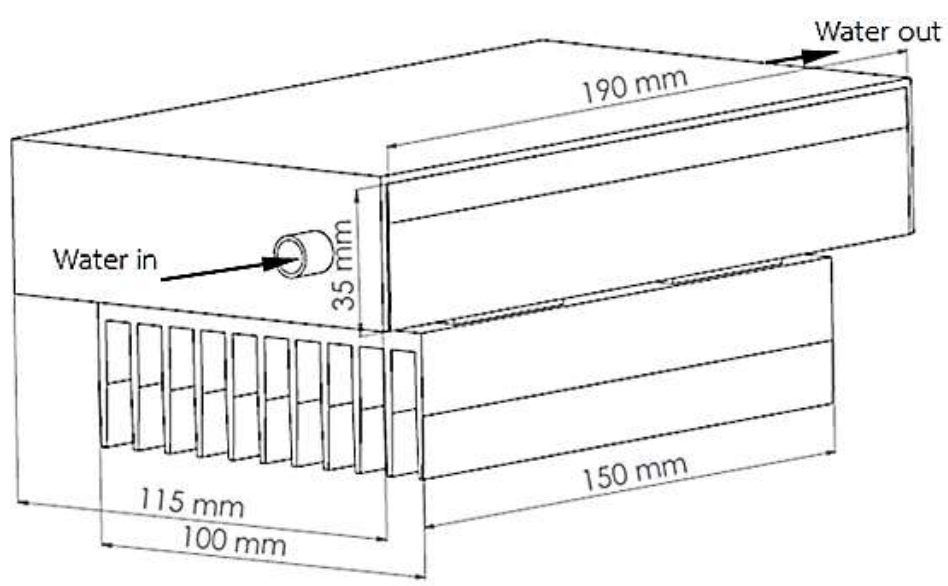

Figure 2. Schematic view of TE dehumidifier

\title{
Experimental uncertainty
}

Uncertainty analysis refers to the uncertainty or error in experimental data. Random errors are varied when the experiments are carried out under constant conditions, but systematic errors are non-variable. Uncertainty is expressed as an interval just about the estimated value. The uncertainty is classified in two types. Type A is related to the random errors and can be determined using iterative and statistical methods while type B is related to systematic errors and can be estimated by gathering the measuring information which is available on data book. For this study, since all the measured data were assumed to have uniform distribution, so that one can consider uncertainty of the data to be of the type B. Thus, the standard uncertainty is calculated by Rahbar el al. [12] as $\mathrm{u}=\frac{\mathrm{a}}{\sqrt{3}}$ where $\mathrm{a}$ is the accuracy of the instrument and $\mathrm{u}$ is the standard uncertainty. Table 1 shows uncertainties of measuring devices.

Table 1 The accuracy, ranges and standard uncertainties associated with the measuring devices

\begin{tabular}{llll}
\hline Instrument & Accuracy & Range & Standard uncertainty \\
\hline T-type thermocouples & $1.0^{\circ} \mathrm{C}$ & $-270-370^{\circ} \mathrm{C}$ & $0.06{ }^{\circ} \mathrm{C}$ \\
Anemometer & $0.03 \mathrm{~m} / \mathrm{s}$ & $0-20 \mathrm{~m} / \mathrm{s}$ & $0.02 \mathrm{~m} / \mathrm{s}$ \\
Relative humidity & $3 \% \mathrm{RH}$ & $10-98 \% \mathrm{RH}$ & $1.73 \% \mathrm{RH}$ \\
Multimeter & $0.1 \mathrm{~A}$ & $0-20 \mathrm{~A}$ & $0.06 \mathrm{~A}$ \\
& $0.1 \mathrm{~V}$ & $0-20 \mathrm{~V}$ & $0.06 \mathrm{~V}$ \\
\hline
\end{tabular}

\begin{abstract}
ANALYSIS
The cooling capacity and the heating dissipated at the cold and hot sides of the TE module can be obtained by applying steady state energy balance for both sides of TE module.
\end{abstract}

The heat dissipated $\left(\mathrm{Q}_{\mathrm{h}}\right)$ is calculated by: [13] 


$$
Q_{h}=\alpha I T_{h}+0.5 I^{2} R-K\left(T_{h}-T_{c}\right)
$$

The cooling capacity $\left(\mathrm{Q}_{c}\right)$ can also determine by

$$
Q_{c}=\alpha I T_{c}-0.5 I^{2} R-K\left(T_{h}-T_{c}\right)
$$

where $\alpha$ is the Seebeck coefficient, $R$ is the electric resistance of the TE module, $K$ is the thermal conductivity of the TE module, $\mathrm{I}$ is the input electric current, $\mathrm{T}_{c}$ and $\mathrm{T}_{h}$ are the cold side and hot side temperatures, respectively. The properties of the TE modules, as presented by the factory, are listed in Table 1 .

Table 2 Properties of TE module [4]

\begin{tabular}{ll}
\hline Seebeck coefficient $(\mathrm{V} / \mathrm{K})$ & 0.0444 \\
Electrical resistance $(\Omega)$ & 2.545 \\
Thermal conductivity $(\mathrm{W} / \mathrm{K})$ & 0.495 \\
Number of elements & 127 \\
\hline
\end{tabular}

The cooling capacity at the cold side is given by rate of sensible heat and latent heat of the air process given by

$$
Q_{c}=M_{a} C_{p}\left(T_{a i}-T_{a o}\right)+M_{w} h_{f g}
$$

where $\mathrm{C}_{\mathrm{p}}$ is the specific heat of air, $\mathrm{h}_{\mathrm{fg}}$ is the latent heat of condensation of water vapor at saturation conditions, $\mathrm{T}_{\mathrm{ai}}$ and $\mathrm{T}_{\mathrm{ao}}$ are the dry bulb temperatures of the process air at the inlet and outlet of the cold side heat sink, respectively, $M_{a}$ is the process air flow rate. $M_{w}$ is the rate of condensed water.

The equation for the COP is given by:

$$
C O P=\frac{Q_{c}}{P}
$$

where $\mathrm{P}$ is the power input to the TE dehumidifier system.

$$
P=P_{T E}+P_{b}+P_{p}+P_{S}
$$

where $\mathrm{P}_{\mathrm{TE}}$ is the power input to TE modules, $\mathrm{P}_{\mathrm{b}}$ is the cold side blower power, $\mathrm{P}_{\mathrm{f}}$ is the radiator fan power, $\mathrm{P}_{\mathrm{p}}$ is the water pump power.

The dehumidification efficiency is defined as the actual humidity ratio drop of the process air to the maximum possible drop. It can be calculated from [3]:

$$
\varepsilon=\frac{H_{a i}-H_{a o}}{H_{a i}-H_{e q}}
$$

where $\mathrm{H}_{\mathrm{ai}}$ and $\mathrm{H}_{\mathrm{ao}}$ are the humidity ratio of the process air at the inlet and exit of the TE cooler, respectively. $\mathrm{H}_{\mathrm{eq}}$ is the air equilibrium at the interfacial area between the air and cold side heat sink. It is calculated from the following ordinary equation [14]: 


$$
H_{e q}=\frac{0.622 P_{v s}}{1.1013 \times 10^{5}-P_{v s}}
$$

where $P_{v s}$ is the partial pressure vapor pressure on the cold side heat sink, which can be found using the water steam table.

\section{RESULTS AND DISCUSSION}

\section{Effect of Electric Current Supply to the TE Modules}

Figure 3 shows the effect of varying the electrical current on the cold side of the TE modules $(\mathrm{Tc})$. Tests were conducted at five difference current levels: $3.5 \mathrm{~A}$ to $18.5 \mathrm{~A}$. When the electric current was increased, the cold side temperature decreased from $17.9^{\circ} \mathrm{C}$ to $9.5^{\circ} \mathrm{C}$. Meanwhile, the cooling water temperature (Two) increased steadily as the electric current increased. At $18.5 \mathrm{~A}$, the maximum cooling water temperature was $34.2^{\circ} \mathrm{C}$ as shown in Figure 3.

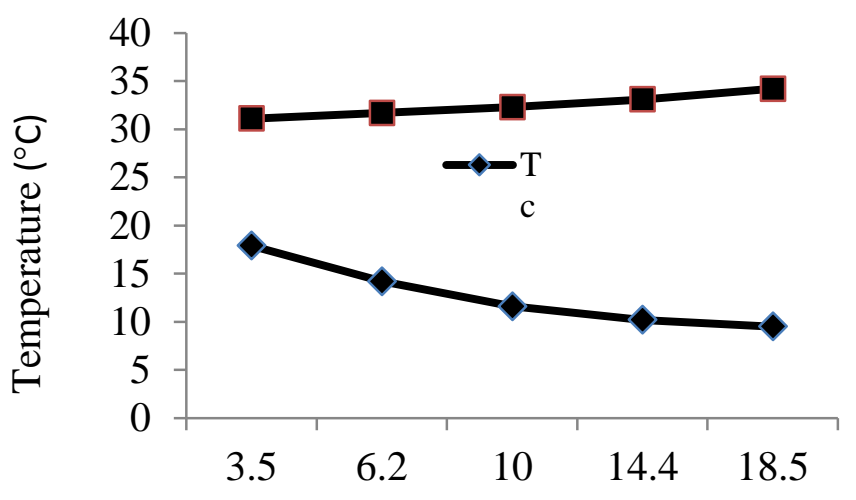

Electric current (A)

Figure 3. Effect of the electric current supply on cold side temperature of TE modules and cooling water temperature (air flow rate: $5.5 \mathrm{~g} / \mathrm{s}$ and ambient temperature: $\approx 30^{\circ} \mathrm{C}$ )

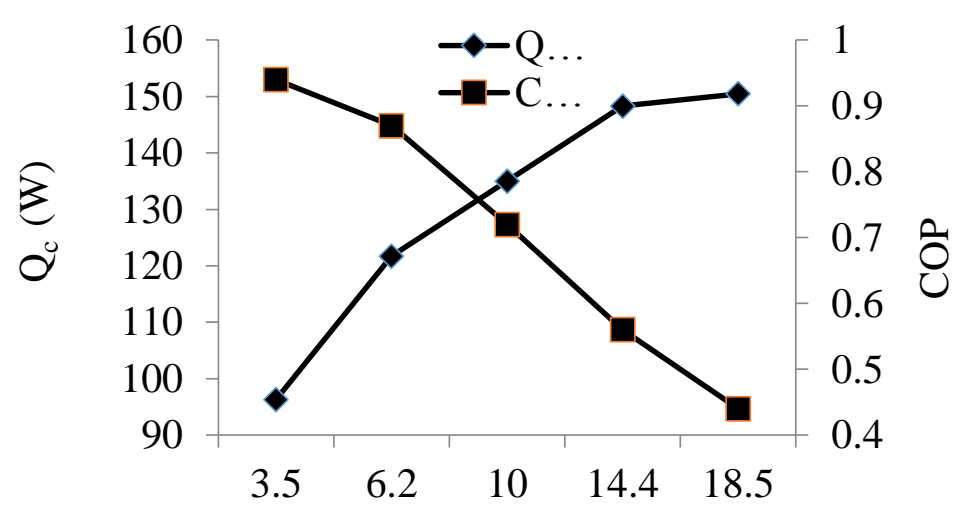

Electric current (A)

Figure 4. Effect of the electric current supply on cooling capacity and COP (air flow rate: $5.5 \mathrm{~g} / \mathrm{s}$ and ambient temperature: $\approx 30^{\circ} \mathrm{C}$ ) 
The cooling capacity $(\mathrm{Qc})$ increased as the electric current increased and reached the maximum value at $150.05 \mathrm{~W}$ at the electric current of $18.5 \mathrm{~A}$ as shown in Figure 4. However, the COP decreased as the electric current increased from 3.5 to $18.5 \mathrm{~A}$. The difference of the COP between electric current of 3.5 and $18.5 \mathrm{~A}$ is $115.9 \%$, while the cooling capacity increased from $3.5 \mathrm{~A}$ to $18.5 \mathrm{~A}$ or about $55.78 \%$. The TE cooling system's high COP usually corresponds to low cooling capacity, and high cooling capacity occurs with low COP. Therefore, TE cooling system optimization process is basically to find the best balance point for both. In this study, a high cooling capacity was chosen to maximize the dehumidifying rate of the TE dehumidifier.

Figure 5. shows the effect of electric current on the cold side heat sink surface temperature (Ts), the difference of humidity ratio between inlet and outlet of the process air $(\Delta \mathrm{H})$ and effectiveness. When the electric current increased, the cold side heat sink decreased. A decrease of cold side heat sink surface temperature decreased the heat sink surface vapor pressure resulting in an increase in the difference between the vapor pressure of the inlet air to the TE dehumidifier and the pressure on the heat sink surface. As a result, the outlet air humidity ratio from the TE dehumidifier is decreased. This result agrees well with that presented by Al-Madhhachi and Min [15]. For dehumidification effectiveness, decreasing the heat sink temperature decreased both the equilibrium humidity ratio on the heat sink surface and that of the outlet air from the TE dehumidifier. Finally, the dehumidification effectiveness slightly increased as a result of the offsetting effects between the numerator and denominator of Eq. (6). Decreasing heat sink surface temperature from $20.1^{\circ} \mathrm{C}$ to $17.9^{\circ} \mathrm{C}$ will increase the dehumidification effectiveness by $13.34 \%$.

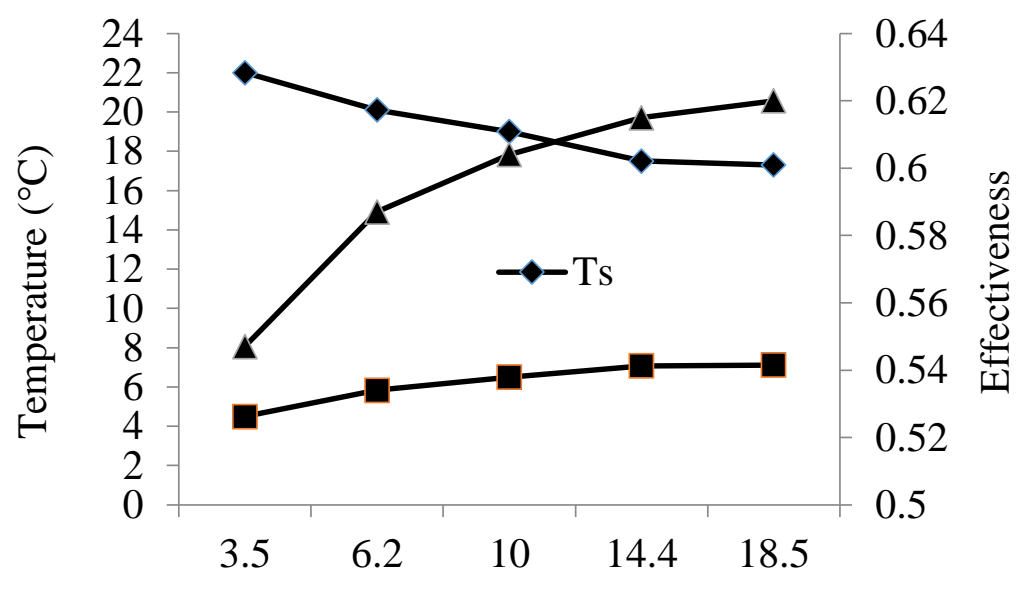

Electric current $(\mathrm{A})$

Figure 5. Effect of the electric current supply on the cold side heat sink surface temperature, difference of humidity ratio between inlet and outlet of the process air and effectiveness (air flow rate: $5.5 \mathrm{~g} / \mathrm{s}$ and ambient temperature: $\approx 30^{\circ} \mathrm{C}$ )

\section{Effect of Air Flow Rate}

Figure 6 shows the effect of air mass flow rate on the difference of humidity ratio between the inlet and outlet of the processed air and the dehumidification effectiveness. When air mass flow rate increased, the difference of humidity ratio from the TE dehumidifier is decreased due to the reduced residence time between air and heat sink surfaces. 
Meanwhile, the dehumidification effectiveness decreased as air mass flow rate increased. When air mass flow rate changed from 5.5 to $27.9 \mathrm{~g} / \mathrm{s}$, the dehumidification effectiveness decreased nearly $38.5 \%$, and the difference of humidity ratio increased by $33.3 \%$.

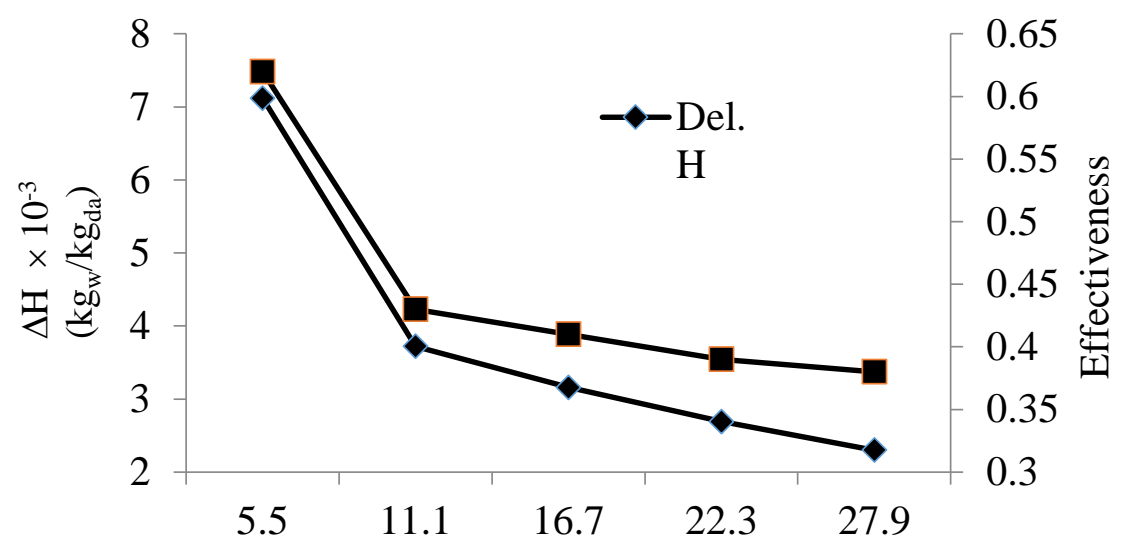

Air flow rate $(\mathrm{g} / \mathrm{s})$

Figure 6. Effect of the air mass flow rate on the difference of humidity ratio between inlet and outlet of the process air and effectiveness (electric current: 18.5 A and ambient temperature: $\approx 30^{\circ} \mathrm{C}$ )

A comparison of performance was made between the present study and the liquid desiccant system [3]. The liquid desiccant system consisted of two cross flow air-liquid desiccant contacting surfaces, named dehumidifier and re-generator; Other components included desiccant solution heat exchanger, desiccant solution cooler, desiccant solution heater, regenerator air fans and desiccant solution pumps (detail in [3]). Table 3 shows a comparison of the COP and effectiveness of the present study and the liquid desiccant system [3]. The COP of the liquid desiccant system was higher than that of the present study, while the effectiveness of the present study was higher than that of the liquid desiccant system. However, the size of the present study was smaller than that of the liquid desiccant system (comparison of air flow rate). If the size of the present study can be increased to be the same as the liquid desiccant system, the COP of the present study may be increased.

Table 3 Comparison between the present study and the liquid desiccant system [3]

\begin{tabular}{llll}
\hline & Air flow rate $(\mathrm{g} / \mathrm{s})$ & COP & Effectiveness \\
\hline The present study & 5.5 & 0.41 & 0.62 \\
The liquid desiccant system [3] & 40 & 0.63 & 0.58 \\
\hline
\end{tabular}

\section{Dehumidification in the Test Chamber}

In this section, the TE dehumidifier was used to reduce the air humidity in the test chamber. The water condensation was $10 \mathrm{~g}$ during the test period of 200 minutes. Figure 7 presents the humidity ratio of ambient air (Hao) and chamber (Hai). The chamber humidity ratio decreased from 0.0021 to $0.0123 \mathrm{~kg}_{\mathrm{w}} / \mathrm{kg}_{\mathrm{da}}$ with the corresponding dehumidification effectiveness of 0.62 , the cooling capacity of $149.5 \mathrm{~W}$ and COP of 0.41 , while the temperature in the chamber dropped by only about $1^{\circ} \mathrm{C}$. However, the TE 
dehumidifier can reduce chamber humidity into the range of thermal comfort conditions of Thailand given by Khedari et al. [16].

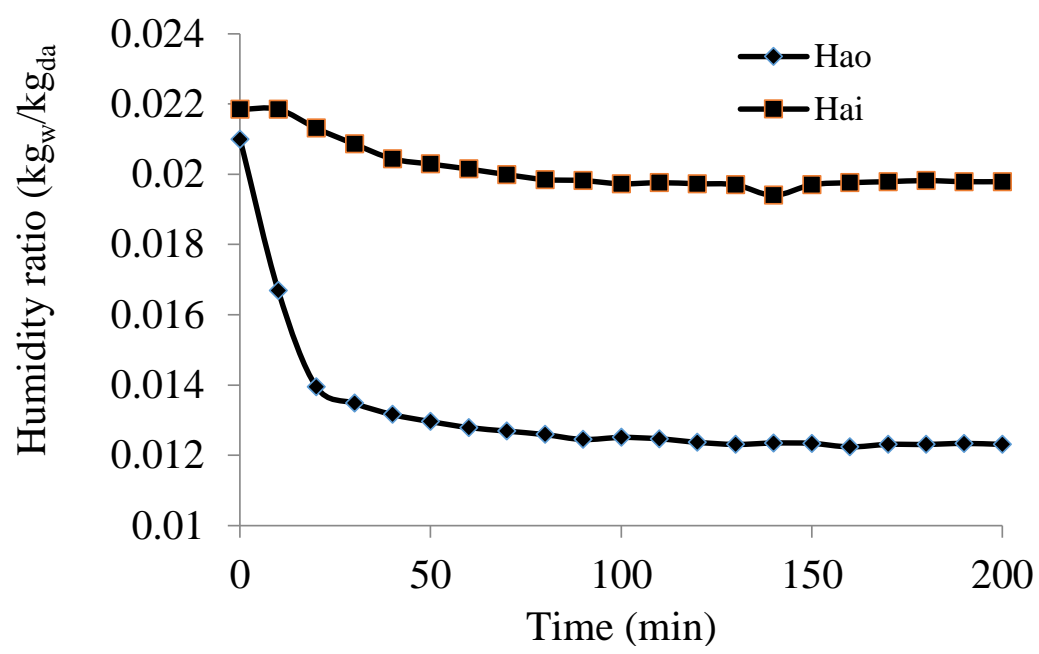

Figure 7 Inlet and outlet humidity ratios versus time (electric current: $18.5 \mathrm{~A}$, air flow rate: $5.5 \mathrm{~g} / \mathrm{s}$ and ambient temperature: $\approx 30^{\circ} \mathrm{C}$ )

\section{CONCLUSIONS}

In this work, a lab-scale TE dehumidifier was fabricated and tested. The dehumidifier was designed based on the principle of a TE cooler. The cold side of the TE modules was utilized for dehumidification purposes, whereas the rejected heat from the hot side of the TE modules was eliminated using heat sinks and a water cooling system. Experimental results showed that the electric current supplied to the TE modules, and air flow rate through the cold side heat sink, exerted significant influence on the COP and effectiveness. An increase in electric current resulted in a decreased COP, and the effectiveness increased with the electric current increased. The prototype can dehumidify the air in the test chamber (volume of $1 \mathrm{~m}^{3}$ ) from 0.021 to $0.0123 \mathrm{~kg}_{\mathrm{w}} / \mathrm{kg}_{\mathrm{da}}$. A suitable condition in this study was found at $18.5 \mathrm{~A}$ of current flow, which gave the dehumidification effectiveness of 0.62 with a COP of 0.41 . The TE dehumidifier can control chamber humidity in the range of Thailand thermal comfort conditions. Finally, the possibility of using a solar cell to drive the TE dehumidification system is an interesting topic for further development.

\section{ACKNOWLEDGEMENTS}

The authors gratefully acknowledge the financial support provide by the Thailand Research Fund (Grant no. DPG5980004) 


\section{REFERENCES}

[1] Atthajariyakul S, Lertsatitthanakorn C. Small fan assisted air conditioner for thermal comfort and energy saving in Thailand. Energy Conversion and Management. 2008; 49:2499-504.

[2] Zafirah MF, Mardiana A. Experimental investigation on the performance of an air-to-air energy recovery for building applications in hot-humid climate. Journal of Mechanical Engineering and Sciences. 2016; 10:1857-64.

[3] Bassuoni MM. An experimental study of structured packing dehumidifier/ regenerator operating with liquid desiccant. Energy. 2011; 36:2528-38.

[4] Lertsatitthanakorn C, Wiset L, Atthanjariyakul S. Evaluating of thermal comfort of thermoelectric ceiling cooling panel (TE-CCP) system. Journal of Electronic Materials. 2009; 38:1472-77.

[5] Rahbar N, Esfahani JA. Experimental study of a novel portable solar still by utilizing the heatpipe and thermoelectric module. Desalination. 2012; 284:55-61.

[6] Yildirim C, Soylu SK, Armaca I, Solmus I. Experimental investigation of a portable desalination unit configured by a thermoelectric cooler. Energy Conversion and Management. 2014; 85:140-5.

[7] Dehghan AA, Afshari A, Rahbar N. Thermal modeling and exergetic analysis of a thermoelectric assisted solar still. Solar Energy. 2015; 115:277-88.

[8] Irshad K, Habib K, Thirumalaiswamy N, Saha BB. Performance analysis of thermoelectric air duct system for energy-efficient buildings. Energy. 2015; 91:1009-17.

[9] Irshad K, Habib K, Basrawi F, Thirumalaiswamy N, Saidur R, Saha BB.Thermal comfort study of a building equipped with thermoelectric air duct system for tropical climate. Applied Thermal Engineering. 2015; 91:1141-55.

[10] Riffat RB, Ma X. Improving the coefficienct of performance of thermoelectric cooling systems: a review. International Journal of Energy Research. 2004; 28:753-68.

[11] Sangmesh B, Gopalakrishna K, Manjunath SH, Kathyayini N, Kadirgana K, Samykano M, Vijayakumar GC. Experimental investigation on HSFP using MWCNT based nanofluids for high power light emitting diodes. Journal of Mechanical Engineering and Sciences. 2018; 12:3852-65.

[12] Rahbar N, Gharaiian A, Rashidi S. Exergy and economic analysis for a double slope solar still equipped by thermoelectric heating modules - an experimental investigation. Desalination. 2017; 420: 106-13.

[13] David B, Ramousse J, Luo L. Optimization of thermoelectric heat pump by operating condition management and heat exchanger design. Energy Conversion and Management. 2012; 60:125-33.

[14] Arora CP. Refrigeration and Air Conditioning. 2nd ed. New Delhi: Tata McGrawHill; 2001.

[15] Al-Madhhachi H, Min G. Ker factors affecting the production in a thermoelectric distillation system. Energy Conversion and Management. 2018; 165:459-64.

[16] Khedari J, Yamtripat N, Pratintong N, Hirunlabh J. Thailand ventilation comfort chart. Energy and Buildings. 2000; 32:245-49. 